Journal Club

Editor's Note: These short reviews of recent JNeurosci articles, written exclusively by students or postdoctoral fellows, summarize the important findings of the paper and provide additional insight and commentary. If the authors of the highlighted article have written a response to the Journal Club, the response can be found by viewing the Journal Club at www.jneurosci.org. For more information on the format, review process, and purpose of Journal Club articles, please see http://www.jneurosci.org/content/ jneurosci-journal-club.

\title{
Importance of Lipids for Nervous System Integrity: Cooperation between Gangliosides and Sulfatides in Myelin Stability
}

\author{
[Giulia Bonetto ${ }^{1 \star}$ and $\mathbb{C}$ Coralie Di Scala ${ }^{2 *}$ \\ ${ }^{1}$ Wellcome-Medical Research Council Cambridge Stem Cell Institute and Department of Veterinary Medicine, University of Cambridge, Cambridge CB2 \\ 1QR, United Kingdom, and 2Institut de Neurobiologie de la Méditerranée, Institut National de la Santé et de la Recherche Médicale U1249, Aix-Marseille \\ Université, 13273 Marseille, France \\ Review of McGonigal et al.
}

Myelin is a modified plasma membrane formed by oligodendrocytes in the CNS and Schwann cells in the PNS (Nave, 2010). Myelination begins with the contact and recognition of the axon by glial processes, which then wrap around the fiber, forming multiple layers of myelin that spread along the axon shaft. Myelin coverage affects the function and molecular organization of axons, speeding signal propagation and reducing energy consumption (Nave, 2010). Myelinated fibers are organized into several domains, including nodes of Ranvier, paranodes, and juxtaparanodes, and the function of each of these regions depends on specific proteins. Paranodes, for instance, are maintained by binding between the cell adhesion molecules Neurofascin-155 (NF155), expressed in the oligodendrocyte, and Contactin and Caspr, expressed

\footnotetext{
Received Feb. 15, 2019; revised June 8, 2019; accepted June 10, 2019.

G.B. was supported by Foundation pour l'Aide à la Recherche sur la Sclérose en Plaques. C.D.S. was supported by Foundation "Gueules Cassées." We thank Dr. Céline Caravagna, Dr. Catherine Faivre-Sarrailh, and Prof. Jacques Fantini for the interesting discussion and remarks on the manuscript.

The authors declare no competing financial interests.

${ }^{*} G$.B. and C.D.S. contributed equally to this work.

Correspondence should be addressed to Giulia Bonetto at gb621@cam.ac.uk or Coralie Di Scala at coralie.di-scala@inserm.fr.

https://doi.org/10.1523/JNEUROSCI.0377-19.2019

Copyright $\odot 2019$ the authors
}

in the axon. These protein interactions are thought to preclude current leakage across the paranodes and thus promote rapid propagation of action potentials (Charles et al., 2002).

Accumulating evidence suggests that lipids, especially glycosphingolipids, are also fundamental for the proper formation and maintenance of myelin (Aureli et al., 2015). Glycosphingolipids, such as gangliosides and sulfatides, are a heterogeneous group of lipids present in the plasma membrane of cells and particularly abundant in the nervous system. Because of their physical-chemical properties, they are highly enriched in the outlet leaflet of the plasma membrane in specialized domains called lipid rafts, where they regulate the spatial organization of membrane proteins (Cantù et al., 2011; Schnaar et al., 2014). At paranodal junctions, for example, NF155, NF186, Caspr, and another essential myelin protein, myelin-associated glycoprotein (MAG), are localized in ganglioside- or sulfatidecontaining rafts. Paranodal regions are abnormal in mice incapable of synthesizing the myelin sulfatides (Marcus et al., 2006), and depletion of gangliosides or sulfatides disrupts myelin and triggers neurodegenerative processes. Furthermore, in mutant mice lacking the complex gan- gliosides GM1 and GD1a in the CNS, the level of Caspr and NF155 in rafts is reduced (Susuki et al., 2007). Despite extensive investigation of the impact of glycosphingolipids on myelin integrity, how these lipids modulate cell membrane proteins remains unclear.

In a recent article in The Journal of Neuroscience, McGonigal et al. (2019) shed some light on this issue, taking advantage of transgenic mouse lines in which glycosphingolipids were selectively depleted from neurons and/or glial cells. Specifically, five lines were used in the study: (1) GalNac- ${ }^{-/-}$(lacking gangliosides); (2) $\mathrm{CST}^{-1-}$ (lacking sulfatides); (3) $\mathrm{CST}^{-1-} \times \mathrm{GalNacT}^{-/-}$(lacking sulfatides and gangliosides); (4) $\mathrm{CST}^{-1-} \times$ GalNac-T $^{-1-}$-Tg (neuronal) (lacking sulfatides and gangliosides globally but with aand b-series gangliosides reintroduced in neurons); and (5) $\mathrm{CST}^{-1-} \times{\mathrm{GD} 3 \mathrm{~s}^{-1-}}^{-1}$ (lacking sulfatides and b-series gangliosides but with conserved a-series gangliosides).

Examination of the membrane proteins involved in axo-glial adhesion and myelin stability (i.e., Neurofascins, Caspr, and MAG) in the optic nerve revealed that, compared with WT, the paranodal structure was modified in every genotype in which glycosphingolipids were altered, except for those lacking only gangliosides 
in neurons and oligodendrocytes (GalNAc- $\mathrm{T}^{-1-}$ mice). A more severe phenotype occurred when sulfatides were absent, as shown by the reduced number of panNFasc (both NF155 and NF186) and Caspr dimers in all lines without sulfatides. Importantly, the strongest phenotype appeared when both gangliosides and sulfatides were altered in both neurons and oligodendrocytes (CST $^{-1-} \times$ GalNAc$\mathrm{T}^{-1-}$ mice), indicating that these two groups of lipids probably cooperate in the myelinating process.

Electron microscopic analysis revealed axonal degeneration and vacuolation in the CNS of $\mathrm{CST}^{-1-} \times$ GalNAc-T ${ }^{-1-}$ mice, whereas electrophysiological experiments showed that the conduction velocity was reduced with diminished glycosphingolipid expression, especially in $\mathrm{CST}^{-1-} \times$ GalNAc-T $^{-1-}$ mice and in those lacking sulfatides and b-series gangliosides $\left(\mathrm{CST}^{-1-} \times \mathrm{GD} 3 \mathrm{~s}^{-1-}\right.$ mice). These data are consistent with previous studies suggesting that mice lacking cerebroside sulfotransferase (CST), the enzyme that catalyzes sulfatide production, have significantly reduced nerve conduction velocity compared with WT mice, both in the CNS and in the PNS (Hayashi et al., 2013).

Interestingly, MAG protein levels in myelin lysates, as well as in whole-brain homogenates, were severely diminished in $\mathrm{CST}^{-1-} \times$ GalNAc- $^{-1-}$ mice compared with genotypes in which at least one group of glycosphingolipid was preserved. Given that the number of mature oligodendrocytes was not decreased, as indicated by the comparable expression of the oligodendrocyte transcription factor 2 (Olig2) across genotypes, the reduced MAG levels resulted from myelin loss rather than oligodendrocyte death. Unlike MAG, however, the expression of other myelin proteins, such as MBP and proteolipid protein, was not modified in the different genotypes. Nevertheless, the organization of myelin proteins might have been altered, even if their expression levels were not.

The study by McGonigal et al. (2019) demonstrates that gangliosides and sulfatides in neurons and oligodendrocytes cooperate to maintain myelination, highlighting the importance of the lipids for membrane protein localization (Fantini and Yahi, 2015). The results suggest that the subcellular localization and function of proteins responsible for axon integrity, including MAG, Caspr, and NF155, are correlated with, and possibly regulated by, the glycosphingolipid content. However, the molecular mechanisms underlying this process are unclear. Do gangliosides and sulfatides directly modulate membrane proteins responsible for axo-glial interaction and myelin integrity? It is possible that glycosphingolipids, by interacting with these proteins, stabilize them at the plasma membrane and regulate their activity. If this is the case, a decrease in glycosphingolipid levels would directly affect the expression, localization, and/or functionality of these proteins. To the best of our knowledge, a direct interaction between NF155 or Caspr and glycosphingolipids has never been described. Notwithstanding, Caspr is localized to lipid rafts via its association with Contactin, which is docked to membrane lipids via a GPI anchor. The cis association of Contactin with Caspr is strictly required for its transport to the cell surface via lipid rafts. Moreover, NF155 is localized in lipid rafts via its trans interaction with Caspr/Contactin (Schafer et al., 2004; Labasque and Faivre-Sarrailh, 2010). Significantly, previous studies have demonstrated that neuronal gangliosides act as receptors for the oligodendroglial protein MAG (Yang et al., 1996), and that this interaction regulates MAG expression and function (Vinson et al., 2001).

An alternative explanation of the results of McGonigal et al. (2019) relates to glycosphingolipid properties. These lipids participate in plasma membrane organization and influence its physical-chemical properties by regulating fluidity, curvature, and raft organization (Cantù et al., 2011; Patel et al., 2016). Therefore, it is possible that the depletion of glycosphingolipids indirectly alters protein expression, localization, and/or activity by changing membrane features. For example, it has been shown previously that the lateral diffusion of myelin-associated proteins, such as MBP and proteolipid protein, within the plasma membrane depends on their lipid environment (Ozgen et al., 2014). Thus, the organization of myelin proteins might be altered, even if their expression levels are not.

Through effects on protein localization, glycosphingolipids might play a role in the dysmyelination or demyelination processes observed in several pathologies. Indeed, various demyelinating diseases, including multiple sclerosis (MS), are associated with alteration of gangliosides and/or sulfatides (Novakova et al., 2018). Differences in the level and nature of sulfatides have been observed, especially in cerebrospinal fluid of patients with progressive MS compared with healthy do- nors or patients with relapsing-remitting MS (Novakova et al., 2018). Surprisingly, in addition to reporting a possible reduction of sulfatide in the normal-appearing white matter of MS patients, Marbois et al. (2000) showed a significant alteration in the sulfatide species present in MS. Furthermore, paranodal deterioration occurs in MS before demyelination: the paranodal clustering of Caspr and NF155 is reduced (Wolswijk and Balesar, 2003; Howell et al., 2006), and juxtaparanodal proteins invade the paranode (Howell et al., 2006). Together with these results, the study by McGonigal et al. (2019) emphasizes the need to better understand lipidprotein interactions and to further elucidate the role of sulfatides and gangliosides in regulating the paranode stability.

\section{References}

Aureli M, Grassi S, Prioni S, Sonnino S, Prinetti A (2015) Lipid membrane domains in the brain. Biochim Biophys Acta 1851:10061016.

Cantù L, Del Favero E, Sonnino S, Prinetti A (2011) Gangliosides and the multiscale modulation of membrane structure. Chem Phys Lipids 164:796-810.

Charles P, Tait S, Faivre-Sarrailh C, Barbin G, Gunn-Moore F, Denisenko-Nehrbass N, Guennoc AM, Girault JA, Brophy PJ, Lubetzki C (2002) Neurofascin is a glial receptor for the paranodin/Caspr-contactin axonal complex at the axoglial junction. Curr Biol 12: 217-220.

Fantini J, Yahi N (2015) Brain lipids in synaptic function and neurological disease: clues to innovative therapeutic strategies for brain disorders. In: Protein-lipid interaction in the brain. Amsterdam: Elsevier, Academic.

Hayashi A, Kaneko N, Tomihira C, Baba H (2013) Sulfatide decrease in myelin influences formation of the paranodal axo-glial junction and conduction velocity in the sciatic nerve. Glia 61:466-474.

Howell OW, Palser A, Polito A, Melrose S, Zonta B, Scheiermann C, Vora AJ, Brophy PJ, Reynolds R (2006) Disruption of neurofascin localization reveals early changes preceding demyelination and remyelination in multiple sclerosis. Brain 129:3173-3185.

Labasque M, Faivre-Sarrailh C (2010) GPIanchored proteins at the node of ranvier. FEBS Lett 584:1787-1792.

Marbois BN, Faull KF, Fluharty AL, RavalFernandes S, Rome LH (2000) Analysis of sulfatide from rat cerebellum and multiple sclerosis white matter by negative ion electrospray mass spectrometry. Biochim Biophys Acta 1484:59-70.

Marcus J, Honigbaum S, Shroff S, Honke K, Rosenbluth J, Dupree JL (2006) Sulfatide is essential for the maintenance of CNS myelin and axon structure. Glia 53:372-381.

McGonigal R, Barrie JA, Yao D, McLaughlin M, Cunningham ME, Rowan EG, Willison HJ (2019) Glial sulfatides and neuronal complex 
gangliosides are functionally interdependent in maintaining myelinating axon integrity. J Neurosci 39:63-77.

Nave KA (2010) Myelination and support of axonal integrity by glia. Nature 468:244-252

Novakova L, Singh AK, Axelsson M, Ståhlman M, Adiels M, Malmeström C, Zetterberg $\mathrm{H}$, Borén J, Lycke J, Cardell SL, Blomqvist M (2018) Sulfatide isoform pattern in cerebrospinal fluid discriminates progressive MS from relapsing-remitting MS. J Neurochem 146:322-332.

Ozgen H, Schrimpf W, Hendrix J, de Jonge JC, Lamb DC, Hoekstra D, Kahya N, Baron W (2014) The lateral membrane organization and dynamics of myelin proteins PLP and $\mathrm{MBP}$ are dictated by distinct galactolipids and the extracellular matrix. PloS One 9:e101834.
Patel DS, Park S, Wu EL, Yeom MS, Widmalm G, Klauda JB, Im W (2016) Influence of ganglioside GM1 concentration on lipid clustering and membrane properties and curvature. Biophys J 111:1987-1999.

Schafer DP, Bansal R, Hedstrom KL, Pfeiffer SE, Rasband MN (2004) Does paranode formation and maintenance require partitioning of neurofascin 155 into lipid rafts? J Neurosci 24:3176-3185.

Schnaar RL, Gerardy-Schahn R, Hildebrandt H (2014) Sialic acids in the brain: gangliosides and polysialic acid in nervous system development, stability, disease, and regeneration. Physiol Rev 94:461-518.

Susuki K, Baba H, Tohyama K, Kanai K, Kuwabara S, Hirata K, Furukawa K, Furukawa K, Rasband MN, Yuki N (2007) Gangliosides contribute to stability of paranodal junctions and ion channel clusters in myelinated nerve fibers. Glia 55:746-757.

Vinson M, Strijbos PJ, Rowles A, Facci L, Moore SE, Simmons DL, Walsh FS (2001) Myelinassociated glycoprotein interacts with ganglioside GT1b: a mechanism for neurite outgrowth inhibition. J Biol Chem 276: 20280-20285.

Wolswijk G, Balesar R (2003) Changes in the expression and localization of the paranodal protein Caspr on axons in chronic multiple sclerosis. Brain 126:1638-1649.

Yang LJ, Zeller CB, Shaper NL, Kiso M, Hasegawa A, Shapiro RE, Schnaar RL (1996) Gangliosides are neuronal ligands for myelin-associated glycoprotein. Proc Natl Acad Sci U S A 93: 814-818. 